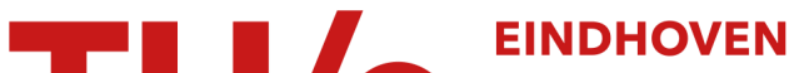 \\ UNIVERSITY OF \\ TECHNOLOGY
}

\section{Policy formulation by use of QFD techniques : a case study}

Citation for published version (APA):

Philips, M., Sander, P. C., \& Govers, C. P. M. (1994). Policy formulation by use of QFD techniques : a case study. International Journal of Quality and Reliability Management, 11(5), 46-58.

https://doi.org/10.1108/02656719410062876

DOI:

$10.1108 / 02656719410062876$

Document status and date:

Published: 01/01/1994

\section{Document Version:}

Publisher's PDF, also known as Version of Record (includes final page, issue and volume numbers)

\section{Please check the document version of this publication:}

- A submitted manuscript is the version of the article upon submission and before peer-review. There can be important differences between the submitted version and the official published version of record. People interested in the research are advised to contact the author for the final version of the publication, or visit the $\mathrm{DOI}$ to the publisher's website.

- The final author version and the galley proof are versions of the publication after peer review.

- The final published version features the final layout of the paper including the volume, issue and page numbers.

Link to publication

\section{General rights}

Copyright and moral rights for the publications made accessible in the public portal are retained by the authors and/or other copyright owners and it is a condition of accessing publications that users recognise and abide by the legal requirements associated with these rights.

- Users may download and print one copy of any publication from the public portal for the purpose of private study or research.

- You may not further distribute the material or use it for any profit-making activity or commercial gain

- You may freely distribute the URL identifying the publication in the public portal.

If the publication is distributed under the terms of Article 25fa of the Dutch Copyright Act, indicated by the "Taverne" license above, please follow below link for the End User Agreement:

www.tue.nl/taverne

Take down policy

If you believe that this document breaches copyright please contact us at:

openaccess@tue.nl

providing details and we will investigate your claim. 
IJQRM

11,5

46

Received October 1993

\title{
Policy Formulation by Use of QFD Techniques: A Case Study
}

\author{
M. Philips, P. Sander and C. Govers
} University of Technology, Eindhoven, T he Netherlands

The quality function deployment (QFD) theory has been developed for application in product design procedures, leading to designs that reflect customer requirements better. M oreover, QFD application to product design can achieve better communication between disciplines in a company such as marketing, design and production and it can lead to shorter design time and less engineering changes after start of production[1,2].

In development and management of annual policy, clear communication and customer orientation is also fundamental for success. Therefore, one might consider the possibility to apply QFD techniques, not in their conventional field, i.e. product design procedures, but to policy formulation and management procedures: if QFD can improve product design procedures towards more customer orientation and clearer communication, perhaps QFD application can do the same to policy formulation or even policy management. In addition, one might benefit from other advantages by doing so, like shorter design time and better integration between disciplines, in this case low er management and higher management, or cross-functional management. Sullivan[3] describes this approach in conceptual terms and he expects valuable progress by such application. How ever, Sullivan[3] does not offer practical reference in his publication.

In this article we will demonstrate how the QFD techniques can be applied to procedures that are used to formulate annual policy. To do so, we will first summarize the QFD theory to get some fundamental insight and then we will explain in which cases customer orientation is necessary for policy management. A fter this, we will outline a conceptual procedure to formulate annual policy based on QFD techniques. We will complete this article with our conclusions on the subject.

To provide practical reference to the concept described here, we will refer to an M Sc graduation project at the Philips EBEI-IC company in Taiwan (Deming prize, 1991), in which one of the authors was involved. This study dealt with such application of QFD techniques to the formulation of annual policy. Other policy management aspects besides formulation, such as control and realization of targets were not covered because of time restrictions.

At the end of each section in this article, we will mention the findings of this study as far as they are related to that section. 


\section{Outline of the Quality F unction Deployment Theory}

A kao[1] describes quality function deployment as an overall concept that provides a means for translating customer requirements into the appropriate technical requirements for each stage of product development and production. A lot of literature is available, describing how to makethis concept concrete and working for a company[1,2] but as far as A merican literature is concerned, many of these publications only deal with QFD applied to product design, especially in the automotive industry.

A Ithough there is some common basis in these QFD publications, different authors have different visions on QFD and, moreover, many of the authors on QFD stress the importance to develop an individual, user specific vision on QFD for successful application. Still, in spite of these different visions, there are some common elements in the publications on QFD theory and the relationship matrix; the so-called House of Quality can be seen as the most important of these basic elements. Figure 1 shows this matrix.

It is used in the following way: a set of items, the "W hats", e.g. customer requirements, is assigned to the rows and a set of items, the "Hows", related to these row items, e.g. engineering characteristics, is assigned to the columns. If the row items carry a numeric relative importance score and if the relations between the row items and the column items are expressed in numeric values, then the relative importances for the column items can also be calculated. Based on these relative importance values, priorities can be set for target setting. Usually, the "W hat" area in the matrix contains the row items and the "W hy" area the related relative importance values. The "How" area contains the column items and the "How vs. How" area their interrelations, the "W hat vs. How" area the relationships with the row items and, finally, the "How much" area the final targets for the column items.

\section{Policy \\ Formulation by \\ Use of QFD}

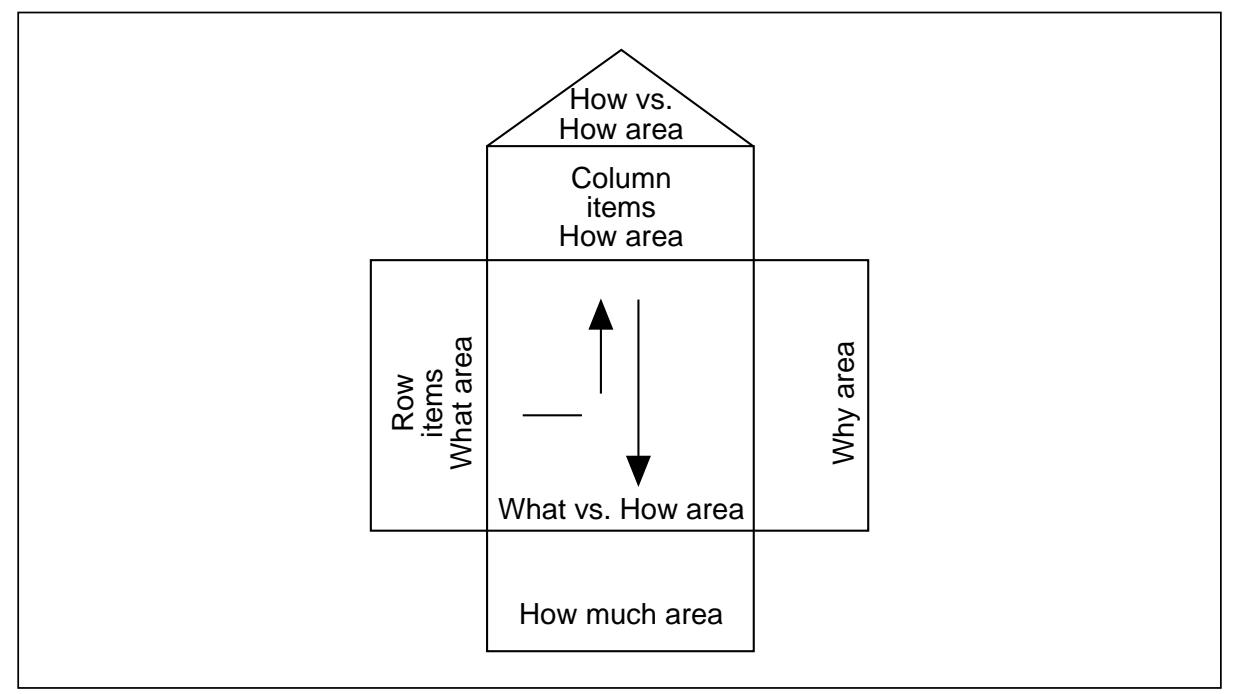

Figure 1 
IJQRM

11,5

Hauser and Clausing[2], as an example of authors on QFD, see QFD as "a set of planning and communication routines that focuses and co-ordinates skills within an organization, from the design stage to manufacturing and marketing of goods that customers want to purchase and will continue to purchase". In their publication, they discuss four relationship matrices in the way shown in Figure 2.

The rows of the first matrix contain the "customer attributes". These customer attributes, or customer requirements, are phrases that the customers use to describe aspects of the product which they find relevant. The columns of the first matrix show the "engineering characteristics", characteristics of the future product that affect its potential to satisfy customers by anticipation on their requirements. T he customer requirements are input, based on market research. The engineering characteristics can be developed by identification of the relationship between engineering characteristics and these customer attributes. If one can assign an importance score to each customer attribute, and if one can reflect relations between customer attributes and engineering characteristics in numerical values, then one can determine how important each engineering characteristic is for customer satisfaction. In this way, it becomes possible to set priorities for engineering characteristics targets in such a way that the product will have specifications that will respond to the identified requirements.

In the second matrix, the rows are formed by the engineering characteristics that were identified in the first matrix. Now, a similar analysis is made to define the most important characteristics of the parts of the product. If the final product must have characteristics that are similar to the engineering characteristics, then what parts of the product should be identified and what must be the essential characteristics of the parts to provide the engineering characteristics in the final end-product? A gain, these parts characteristics are identified by analysis of the relationship between engineering characteristics and part characteristics. If the engineering characteristics are well specified, then, specifications can also be made for the parts characteristics.

\section{Figure 2.}

The Four Houses of Quality A ccording to Hauser and Clausing[2]

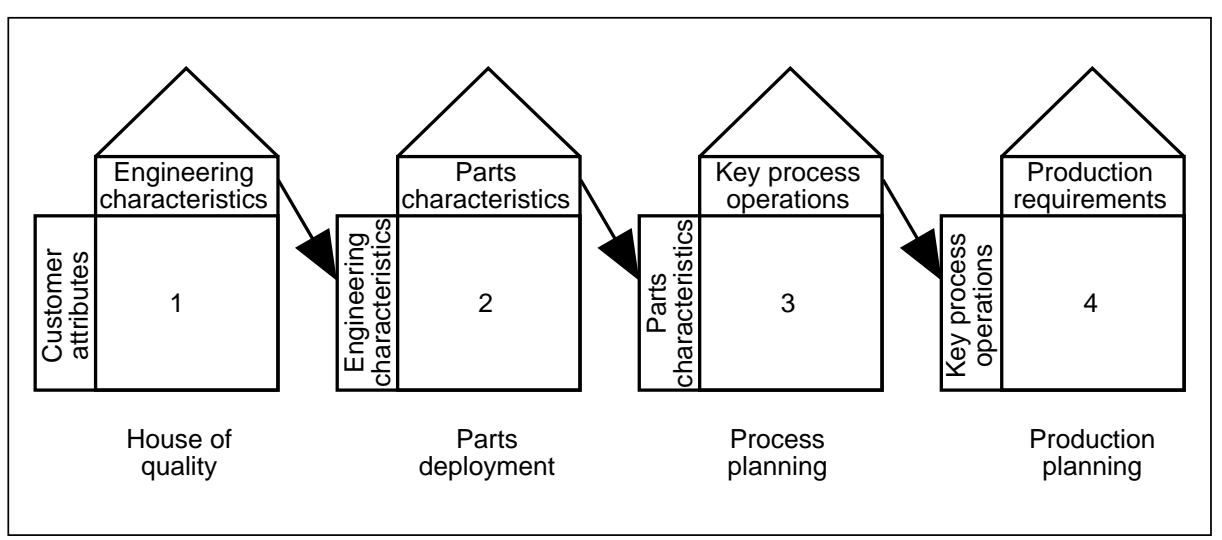


In a similar way, the other two matrices can be developed: from the characteristics of the parts of the product, the key process operations can be developed and specified. In this way it becomes clear what processes should be used to manufacture the parts. Finally, from the key process operations, the production requirements can be developed and specified, to find out how the process operations can be realized. This is in short what Hauser and Clausing mean by QFD. Product design, process planning and manufacturing control need specialists from different disciplines to create products that have more potential to satisfy customers, as the product will be based on customer requirements.

\section{QFD at PEBEI-IC}

Philips EBEI-IC is an assembly factory for integrated circuits (ICS). The primary activity of the company is to assemble silicon crystals into ICs which can be built into electronic devices. PEBEI-IC is not involved in development of functional specifications of the ICS, i.e. the architecture of the electronic circuit on the crystal, but it is involved in development of physical specifications package development. For this package development in past years, an individual vision on how to apply QFD has been developed and the experience with QFD is rather good. A Ithough PEBEI-IC is not directly involved in the marketing of its products, the QFD methodology provides means to translateall information that is available into product characteristics and it provides means to take earlier experience with the assembly process in account. Furthermore, QFD is experienced to be valuable as a communication tool and an integrator of functions. In addition, the information in the matrices of earlier designed packages is a very good starting point when new items of a product family are to be developed.

\section{The Reasons for A pplication of QFD to Policy Management}

Now the QFD theory is summarized in its current field, product design, it will be explained why customer orientation and good communications can be essential in the policy management field. To do so, one might consider the following example of a strip steel manufacturer, which is adapted from Levitt[4].

Imagine you are selling strip steel. A nd imagine that, along with you, many competitors are aiming at the same group of customers - the buyers of No. 302, 72-inch, hot-rolled strip. In that case, you might want to compete and gain the favour of your customers to stay in the market. Now, what you cannot do is compete by offering a better product than the competition brings to the market, as everybody offers the same No. 302, 72-inch, hot-rolled strip steel and nothing else. In addition, it will be difficult to offer a lower price than your competitors do, as that is what you and your competitors have been trying to do for the last few years. What you can do however, is compete on other product aspects, "secondary" product aspects that are not specifically product or price related, but which in your case may be the aspects that might decide on your success on 
IJQRM 11,5

the market. Examples of such in the strip steel case may be: delivery aspects, like speed of delivery, reliability of delivery; terms, like discount structures related to promptness of payment, or add-on provisions for extended payment periods; support efforts, e.g. advice and support for special applications of the product; new ideas, like suggestions for more efficient and cost reducing use of the product.

Companies that find themselves in a market situation similar to the example do not only need to pay attention to product design based on customer requirements to establish "primary" product aspects that can satisfy customers. They also need to pay attention to the process that establishes these secondary aspects. They need to take customer requirements into account when targets are set for improvement in the overall company performance, e.g. in their development and realization of annual policy. Of course, companies to which these secondary products are essential need to develop a policy based on these customer requirements to realize real customer satisfaction.

This standpoint is shared by Shapiro[5], who gives a more general approach to the problems related to competing on such second-type markets by dealing with market oriented management. Although he does not mention QFD as a tool for policy management, he stresses the need for management based on customer requirements and open communication lines within the company.

The Relevance of Policy M anagement at PEBEI-IC

From the start of the study at Philips EBEI-IC, it was assumed that for PEBEI$I C$, the secondary product aspects of the end products are relevant to customers. This assumption was made as the specifications of IC-packages, the primary product aspects as far as Philips EBEI-IC is concerned, are in general standardized. ICs from competitors are not very different regarding the design of their packages, so secondary product aspects become relevant.

Later in the study, when marketing specialists were interviewed, this assumption appeared to be true. Customers in the IC business seem to use rather more secondary product aspects to evaluate their IC suppliers. To them, functional and physical specifications of ICs are mostly standardized and hard to use as selection criteria for suppliers. The opposite is true for product aspects such as delivery time, delivery reliability and service in case of support or complaint.

From this point of view it was decided that the process which determines the performance on these product aspects, the annual policy formulation procedure, should be a subject of study. More specifically, it was decided to investigate how customer information was used at that time to set improvement targets for company performance, and it was further investigated if application of QFD to this process could lead to improvement of this practice.

Policy formulation, as a part of policy management, was considered in the study. Other parts, like realization and control of policy were not considered. A ccording to Hauser and Clausing[2], one might conclude that from the QFD theory only the first matrix was taken in account: to consider the whole process 
of policy management, one should apply the four matrices. Here, only policy formulation and therefore only the first matrix was considered.

\section{A pplication of QFD to Annual Policy Management}

With the concept of the foregoing section in mind, one might now wonder what QFD can do for policy management and how it can be applied to policy management. A conceptual procedure for such application will therefore be outlined in this section but first, a closer look will be taken at policy management itself.

In an annual policy, the most important performance indicators for a division or company are identified and targets for improvement are set. In general, an annual policy determines which aspects of company performance will improve and which will remain the same in the coming year. On the one hand such determination is typically made based on the ability to improve; one might think of internal strengths and weaknesses and, on the other hand, on opportunities and threats in the environment which it is possible to anticipate. These opportunities and threats can be the result of an analysis of past performance of the company and developments in the market. Usually, when an annual policy is developed, it is related to higher goals like higher management policy, e.g. business-unit policy, realization of long-term plans or the mission statement.

A fter determination of the improvement targets, they need to be deployed to people who will take responsibility. Then, improvement actions have to be defined to reach the target. Finally, a control system should be there to monitor progress and to take necessary action if needed.

Like the QFD procedure to design products according to Hauser and Clausing[2], the QFD procedure to develop and manage annual policy could also consist of four matrices. As one might notice, filling in the first matrix could be a roughly similar process as determination of policy based on strengths, weaknesses, opportunities and threats, as in both procedures targets are set based on an external and an internal analysis. Figure 3 shows the conceptual procedure, similar to Figure 1. Now, in the procedure described here, it will be made clear how this first matrix can be filled in when policy is formulated.

The first relationship matrix will contain customer requirements in the rows and control items or performance indicators in the columns. To obtain customer requirements, one will first need a definition of the target customers of policy. In product design procedures target customers are mostly a coherent group, but policy needs to satisfy various groups like the end-users, the higher management and the company itself.

From the end users, customer requirements can be obtained by market research, similar to an inventory of opportunities and threats in the environment. Typically, the secondary product aspects that are essential for customer satisfaction will appear here. Requirements from higher management can, for example, be found in the business unit policy or the company policy. They contain the requirements from higher management, for higher

\section{Policy \\ Formulation by Use of QFD}




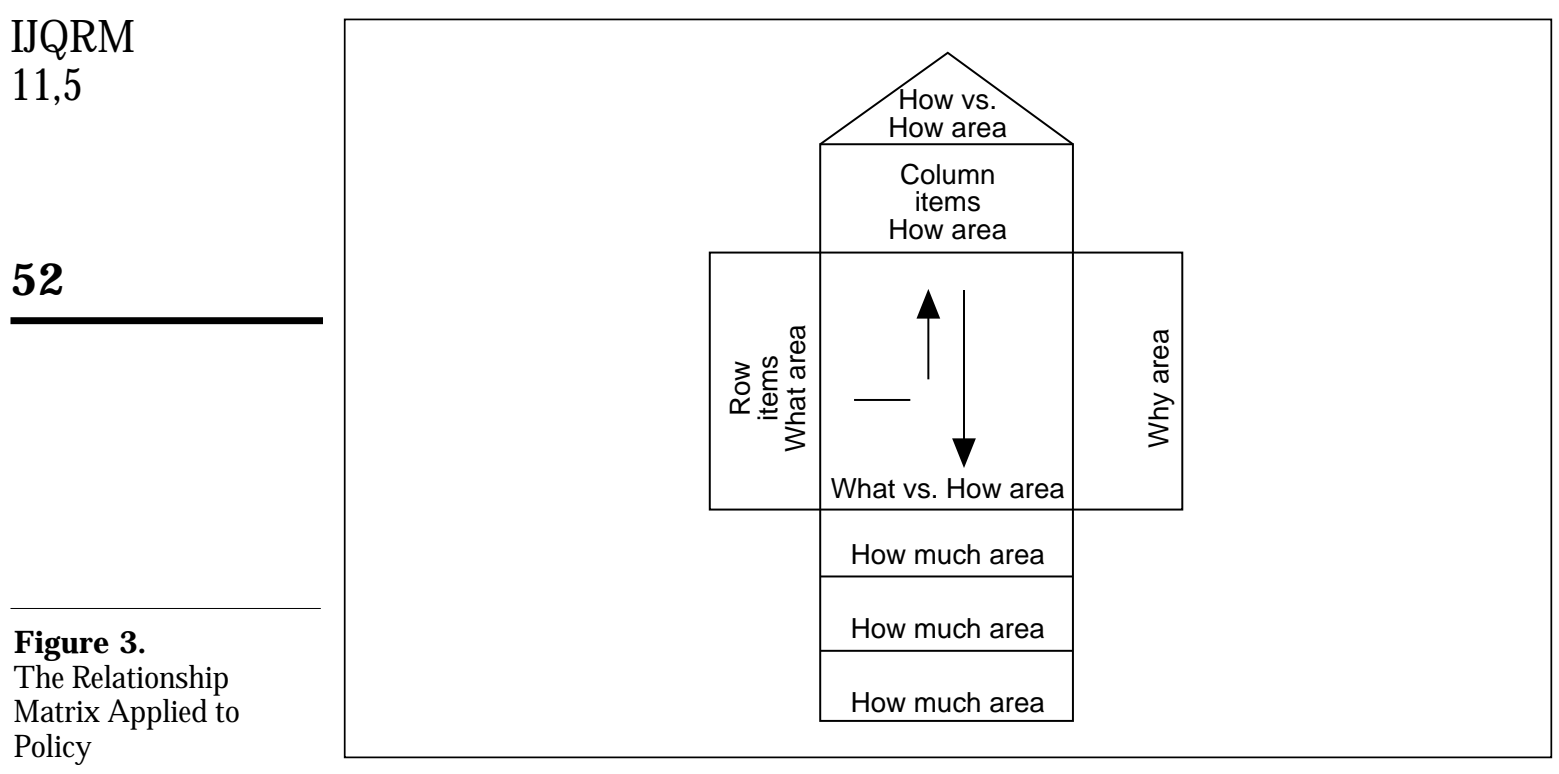

management satisfaction. Finally, requirements of the company itself could be reflections of the company's mission statement or its long-term plan. In this way, a list of customer requirements can be developed which can be filled into the first matrix as row items. To calculate the need for improvement on the performance indicators, importance values should be assigned to each of the customer requirements. These importance values should reflect how important they are for customer satisfaction. However, dealing with different groups of customers, these importance values should not only be based as the priority in the eyes of the customer, but also on the importance that the company assigns to the group of customers itself. If the company wants to pay much attention to higher management requirements, then the high priority items of higher management should have a higher importance value than high priority items from end users. Here, the power of the hierarchy in a company will appear and become explicit. Companies with strong ties to higher management or business unit management will almost invariably pay attention to their requirements to satisfy them. Companies which are relatively or totally independent will assign a high weight to end users. In the QFD chart, the customer requirements can be put in the "W hat" area and the importance values of each requirement can be put in the "W hy" area.

When the customer requirements and their importance values are obtained, one can start with development of the set of company performance indicators by identification of the relationship between performance indicators and customer requirements. If a company wants to anticipate a customer requirement, then it has to start with the identification of a relationship between that customer requirement and a performance indicator. In addition, if a 
company wants to anticipate a customer requirement, then it has to consider which performance indicators, al ready defined, are related to that requirement. A fter identification of all performance indicators, one might investigate which relationships exist between them. The results of this investigation can be put in the "attic" of the matrix, the "How vs. How" area. It will provide insight in the way in which performance on one item affects, positively or negatively, the performance on other items. Later, when targets are set, these inter relations can be taken in account.

Now, if improvement in performance of the identified indicators is realized, then the company anticipates on the identified customer requirements. It will be clear that all customer requirements should be related to at least one performance indicator if one wants to anticipate on all requirements. Furthermore, the extent to which customer satisfaction is created depends, of course, on the amount of improvement that is realized, but, moreover, also on the strength of the relationship between the customer requirements and the performance indicator. This strength of the relationship should also be estimated and expressed in a numeric value in the matrix. The performance indicators can be summed up in the columns of the matrix, in the "How" area. The relationship values can be allocated to the rows and the columns in the matrix, the "W hat vs. How" area.

To complete the first matrix, the "How much" needs to be filled in. In the upper "How much" area, one might give the result of a calculation that shows how important improvement is on each performance indicator. Such calculation can be made by multiplication of the weights of all relations of an indicator to the customer requirements that are related. M ore advanced techniques than this are described by Hales[6]. In the study, these advanced methods were used, but for the moment they will not be discussed.

In the middle "How much" area, one may put the relative ability to improve the performance item. These values may be the result of an internal analysis, which provides insight in the relative ability for the company to realize improvement in that area. These values can be based on findings or estimations of the responsibilities for that performance item, or from sources like benchmarking.

In the lower "How much" area, one may finally enter the targets to be set for each performance item. These targets can now be based on the one hand on need for improvement, established in the upper "How much" area and on the other hand on the ability for improvement, summarized in the middle "How much" area. If, for instance, the priority for improvement is relatively high, as the indicator has many strong relationships with important customer requirements, and there is relatively much opportunity for improvement, then the upper two values in the "How much" area are relatively high. This justifies a high improvement target. However, if both values are low, then the target should not be set too optimistically. Finally, if one of the values is relatively high and the other is relatively low, then management should find some balance. In this way, targets for performance indicators can be set, based on internal and
53 
IJQRM

11,5

54

external analyses, similar to the conventional QFD applications and the strengths, weaknesses, etc. applications.

A fter filling in this first matrix, one might use the following three matrices for the other aspects of the policy management process. In the second matrix, the performance indicators can be listed in the rows. Now, the analysis will be directed to the (sub-)indicators which are needed to establish the targets of the company. A Iso, for these (sub-)indicators, targets can be set if ability for improvement on these is measured and if importance for improvement is clear. In the third and fourth matrix, it can be made clear what changes have to be made to realize the identified targets and under what circumstances these changes have to take place (which things have to be controlled to manage the change process).

\section{QFD Oriented Policy Formulation at PEBEI-IC}

A t PEBEI-IC, the described concept procedure served as a reference for the procedure that was used in practice to formulate the policy and targets for 1993. As mentioned in the foregoing section, the aim of the study at PEBEI-IC was to see how customer information was used for policy formulation and if this use could be improved by application of QFD methods. To reach this aim, it was planned to make a schedule of the practices of policy formulation at PEBEI-IC that could be compared with a conceptual procedure to formulate policy based on QFD theory. The differences between the two could then be areas for improvement and this would givesome indication of the applicability of QFD in this field. A ccording to this plan, the study was conducted. It led to five main differences and improvement areas between both procedures and they will be discussed below. First, how ever, it will be explained how policy was formulated in practice.

To describe the activities to formulate 1993 policy, one might distinguish four steps. The first and second are analyses of internal and external factors and the third and fourth are activities to develop policy based on the external and internal analyses.

For the internal analysis, first the performance indicators for 1993 were identified by taking into account the guidelines of the PEBEI-IC long-term plan and the superior organizations, in this case the product division Semiconductors of Philips and the Philips Taiwan National organization. Then, performance on the newly identified indicators was measured and an estimation was made of the potential of the company to improve on these items, by making an estimation of a realistic target for the following year.

The external analysis was based on the requirements of the superior organizations and on an environmental analysis. This environmental analysis was comparable to a strengths and weaknesses, opportunities and threats analysis, in which a customer satisfaction survey and a brainstorming session at PEBEI-IC provided the opportunities and threats and the performance and benchmarking information on the new performance indicators the strengths and weaknesses. 
These two analyses provided insight into the realistic possibilities for improvement and necessity for improvement. Based on these two, the third and fourth steps were taken: initial targets were set and discussed with the people who would be accountable for future performance. In addition, the outline for 1993 policy was written. Based on the results of the discussions, targets were set and proposed to management as the policy and the improvement plan for 1993. A fter approval of these plans, the targets were made definitive and a plan for execution and improvement was developed.

A s mentioned, these activities were compared with the conceptual QFD procedure that is summarized above. In spite of the fact that the two procedures have roughly the same structure (but are different in many details), this QFD approach identified five main differences that can become areas for improvement:

(1) The first difference is the fact that in the QFD procedure, a clear definition of the customers of policy is required and, moreover, a consideration is required on how important the requirements of the different customers are. In the current procedure, there is some common understanding of the customers of policy, but this definition is not sufficient for the QFD procedure, as it does not provide clarity on how important the requirements of different customers are.

It must be noticed that the term "customer of policy" is rather fundamental but not commonly used. To understand who the customers of policy are, one needs to consider that improvement targets must have a reason for being: they are set for a specific reason - to create satisfaction for people or organizations around the company. They judge and evaluate company performance and performing well for them is an objective for the company: they are the customers of policy.

(2) A s a second difference one might notice that there is not sufficient insight into the value of the information that is obtained from end-users. Here also, one has some insight into the value of the information obtained by the customer satisfaction survey, but this is not sufficient if one wants to estimate how important the requirements of end-users are which result from this group of customers.

(3) Third, no explicit analysis is made of inter relations between performance indicators. In the QFD procedure such analysis is made and it provides insight into the possibilities that appear when improvement on one performance indicator is realized.

(4) The QFD procedure uses numeric values to express information. On the one hand, sometimes this can be very difficult, as rough estimations will have to be made, but it provides the possibility to make calculations and to draw more objective conclusions from the information.

(5) Finally, the QFD procedure makes use of one chart that contains all relevant information with the advantage that it becomes easier to
Policy
Formulation by
Use of QFD

55 
IJQRM

11,5

oversee the whole process. In the procedure at PEBEI-IC, different forms were used which made it a little more difficult to obtain an insight into the reasons for decisions.

A fter identification of these areas of potential improvement, two were taken out to see if they really could lead to improvement. They were the second and the fifth items. To start with the second, a short survey was held among the marketing organizations in South East A sia. The aims of this survey were to motivate these organizations to co-operate more closely on the exchange of customer information and to obtain feedback from end-users which could be input to 1993 policy. Besides, with this information, there would be more insight into the question of how representative the information is of the customer satisfaction survey. On this survey, a response rate of only 20 per cent was realized which made the results difficult to use. It was concluded that for better understanding on the value of customer information, close interaction with the other organizations would be necessary and that a survey, as it was sent out, was not the appropriate means to create that co-operation. F urthermore, an interview was held with the management of the marketing organizations about South- East A sia. This interview was more successful and provided useful information on policy, although the level of detail was not appropriate to estimate the value of the other obtained information.

Finally, to gain experience with the fifth area of improvement, the QFD chart was completed with the information from 1993 policy. A part of the matrix that was obtained in this way is shown in Figure 4. This initiative turned out rather successfully: the advantages of one chart instead of several forms appeared to be realistic. A Iso, in policy formulation, QFD charts are able to contain all relevant information from customer input to target setting.

\section{A dvantages of A pplication of QFD to Policy Formulation}

In some cases it can be necessary for a company to perform well on secondary product aspects if it wishes to stay in the market. One way to do so is to listen to the customer requirements when the annual policy of the company is developed. QFD is a concept that structures customer requirements and makes them more explicit, as far as primary products are concerned if it is applied to product design. In addition, if the concept of QFD is applied to annual policy management, then it also becomes possible to listen to secondary customer requirements and take them in account. Similar to the product design application, one might expect other benefits, like reduction in time and costs needed for policy development and greater clarity in the whole path of policy design and realization.

Especially in the field of better integration of different disciplines, QFD may lead to improvement: QFD application to policy management will create a very strong basis for cross-functional management on policy level and it will create a strong link between, e.g. the marketing department and the people responsible for policy formulation, and similarly between those responsible and 


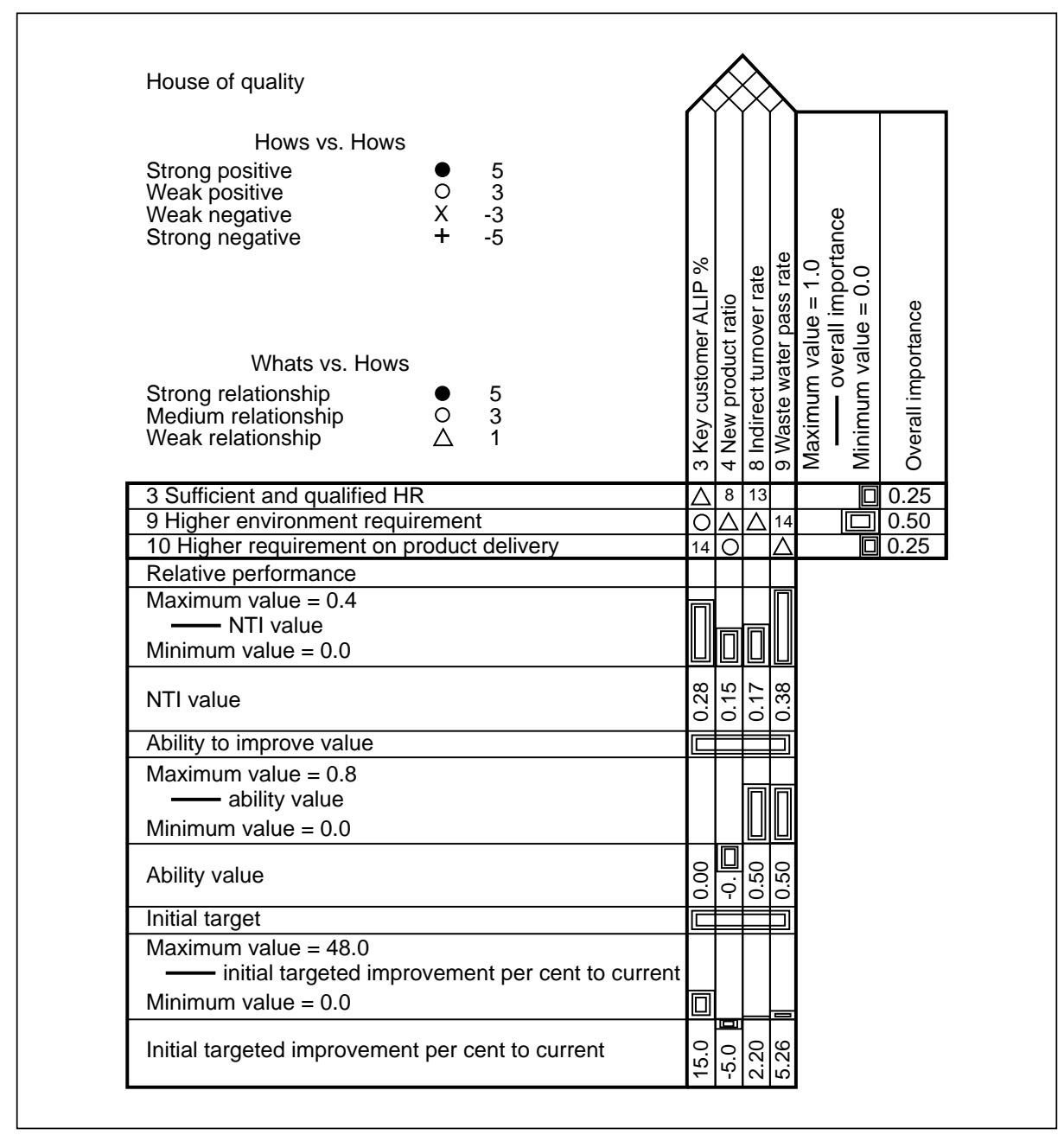

\section{Formulation by Use of QFD}

57

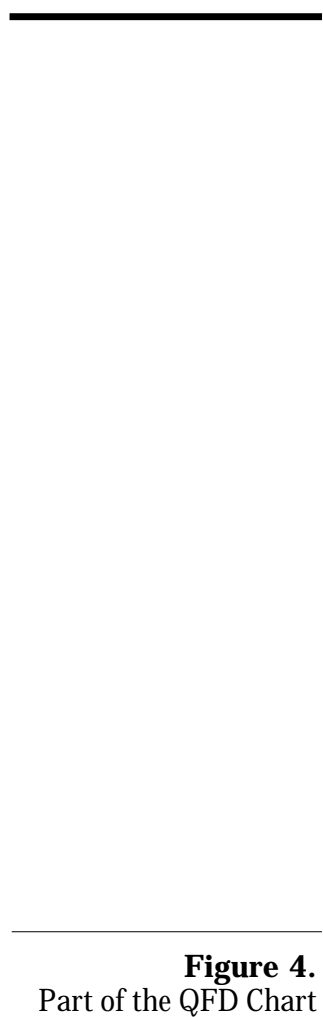

the people who take responsibility for achievement of policy. So, better links, based on customer requirements, both horizontally and vertically are established.

QFD applications to policy management may be especially successful in situations in which customer requirements and company performance change rather slowly. A s experienced in QFD applications to product design, QFD results in a lot of work in the case of designs of entirely new products. However, if product families are designed or existing products are modified, then this time can be regained as changes can be made easily and thoroughly. Similarly, in situations in which policy is entirely new every year as a result of fast internal and external changes, then QFD application will lead to much work. But if an annual policy can be seen as a (slight) modification of the previous year's policy 
IJQRM 11,5 as a result of slow changes - a more probable assumption - then these changes can be taken into account quickly and thoroughly, as the previous year's chart can be the basis for the following year.

\section{Conclusions of the Study}

The Philips EBEI-IC study revealed that QFD theory can be a very inspiring source for improvements in policy formulation. A lthough there is no proof that QFD is an unconditional guideline to excellence in policy management, QFD application revealed five specific items to assist in the improvement of current procedures. Further study and attention to adaption of more QFD techniques in policy management will pay off.

A pplication of QFD in this field showed that advantages of QFD can be realized, not only in product design, but also in policy formulation. A lthough many problems were encountered on the way, it became clear that these problems had to be faced to obtain improvement of the current system. QFD functioned here not so much as a problem solver, but rather as an indicator of problems that have to be faced if one wants to improve towards more customer orientation and better communication in the policy formulation process.

\section{References}

1. A kao, Y., Quality Function Deployment, Productivity Press, Cambridge, MA, 1990.

2. Hauser, J.R. and Clausing D., "T he House of Quality", Harvard Business Review, May-June 1988.

3. Sullivan, L.P., "Policy Management through Quality Function Deployment", Quality Progress, June 1988.

4. Levitt, T., "Marketing Success through Differentiation - of A nything", Harvard Business Review, January-February 1980.

5. Shapiro, B.P., "W hat the Hell is 'M arket Oriented'?", Harvard Business Review, NovemberDecember 1988.

6. Hales, R., Lyman, D. and Norman, R., Quality Function Deployment and the Expanded House of Quality, International Technogroup Incorporated, 1990.

\section{F urther Reading}

Sullivan, L.P., "Quality Function Deployment", Quality Progress, June 1986. 